\title{
Numerical Shear Tests on the Scale Effect of Rock Joints under CNL and CND Conditions
}

\author{
Xige Liu (D), Wancheng Zhu (D), and Lankun Li iD \\ Center for Rock Instability and Seismicity Research, School of Resource and Civil Engineering, Northeastern University, \\ Shenyang 110819, China
}

Correspondence should be addressed to Wancheng Zhu; zhuwancheng@mail.neu.edu.cn

Received 2 January 2020; Revised 8 April 2020; Accepted 16 May 2020; Published 24 August 2020

Academic Editor: Liborio Cavaleri

Copyright $(2020$ Xige Liu et al. This is an open access article distributed under the Creative Commons Attribution License, which permits unrestricted use, distribution, and reproduction in any medium, provided the original work is properly cited.

The scale effect of rock joint shear behavior is an important subject in the field of rock mechanics. There is yet a lack of consensus regarding whether the shear strength of rock joints increases, decreases, or remains unchanged as the joint size increases. To explore this issue, a series of repeated and enlarged numerical joint models were established in this study using the particle flow code (PFC2D). The microparameters were calibrated by uniaxial compression tests and shear tests on the concrete material under the constant normal loading $(\mathrm{CNL})$ condition. Three different normal stresses were adopted in numerical shear tests with joint specimen lengths ranging from $100 \mathrm{~mm}$ to $800 \mathrm{~mm}$. In addition to the commonly used CNL, the constant normal displacement (CND) condition was established for the purposes of this study; the CND can be considered an extreme case of the constant normal stiffness (CNS) condition. The shear stress-shear displacement curves changed from brittle failure to ductile failure alongside a gradual decrease in peak shear strength as joint length increased. That is, an overall negative scale effect was observed. Positive scale effect or no scale effect is also possible within a limited joint length range. A positive correlation was also observed between the peak shear displacement and joint length, and a negative correlation between shear stiffness and joint length. These above statements are applicable to both repeated and enlarged joints under either CNL or CND conditions. When the normal stress is sufficiently high and shear dilatancy displacement is very small, the shear behavior of rock joints under CNL and CND conditions seems to be consistent. However, for shear tests under low initial normal stress, the peak shear strength achieved under the CND condition is much higher than that under the CNL condition, as the normal stresses of enlarged joints increase to greater extent than the repeated ones during shearing.

\section{Introduction}

Scale effect, including the shear behavior of rock joints, exists widely in rock engineering scenarios. A common approach to quantifying the shear strength of large rock joints is to conduct shear tests on small rock samples in the laboratory, then establish a relationship with large-scale rock joints. Barton et al. [1-5] have explored both aspects of rock joint shear testing and achieved a series of influential results.

The empirical equation (1) proposed by Barton and Choubey $[3,4]$ can be used to estimate the peak shear strength $\left(\tau_{\text {peak }}\right)$ of a rock joint; it was obtained from shear tests on $136100 \mathrm{~mm}$ long rock samples. Ten typical profiles were utilized to quantify the JRC value for a small rock joint specimen (Table 1) by visual assessment using equation (1). The relationship between small rock joints and large ones is given by equations (2) and (3) $[1,2]$. These equations can be used to determine the $\tau_{\text {peak }}$ of a large rock joint.

$$
\begin{aligned}
\tau_{\text {peak }} & =\sigma_{n} \tan \left[\operatorname{JRClog}\left(\frac{\mathrm{JCS}}{\sigma_{n}}\right)+\varphi_{\mathrm{b}}\right], \\
\mathrm{JRC}_{n} & =\operatorname{JRC}_{0}\left[\frac{L_{n}}{L_{0}}\right]^{-0.02 J \mathrm{JC}_{0}}, \\
\mathrm{JCS}_{n} & =\mathrm{JCS}_{0}\left[\frac{L_{n}}{L_{0}}\right]^{-0.03 \mathrm{JC}_{0}},
\end{aligned}
$$

where $\sigma_{n}$ is the normal stress applied on the joint surface, JRC is the joint roughness coefficient, JCS is the joint wall 
TABLE 1: Ten typical roughness profiles [3].

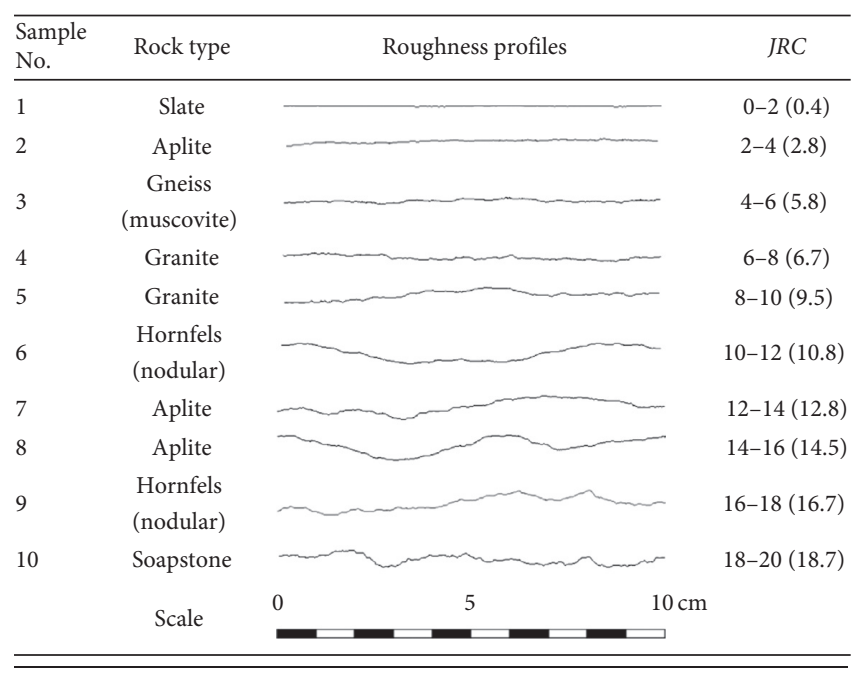

compression strength, and $\varphi_{\mathrm{b}}$ is the basic friction angle. The subscripts $n$ and 0 of JRC and JCS in equations (2) and (3) refer to the in situ and normal size $(100 \mathrm{~mm})$, respectively.

Equations (2) and (3) show that the $\tau_{\text {peak }} s$ of rock joints decrease as joint size increases. This is generally referred to as "negative scale effect." Many previous researchers have observed similar results in physical or numerical shear tests (e.g., [6-17]). Other scholars, however, have observed "positive scale effect," where $\tau_{\text {peak }}$ increases with joint size (e.g., [18-20]). Others have found that no obvious scale effect occurs in shear tests (e.g., [21-26]). There is no consensus on this issue, largely due to the inherent difficulty of carrying out large-scale rock joint shear tests.

The shear test method adopted by Ueng et al. [26] involves reducing, enlarging, and assembling one joint profile unit ranging from $75 \mathrm{~mm}$ to $300 \mathrm{~mm}$, which is convenient for analyzing the scale effect of rock joints. No obvious scale effect was observed in proportionally enlarged and reduced joints in their direct shear tests, which may be due to a limited range of rock joint length. Particle size effects do not readily appear when the joint length is limited. By contrast, numerical simulations allow for shear tests on large-scale joints without size limitations. Bahaaddini et al. [7] conducted numerical shear tests in PFC2D software to find easily observable negative scale effect on the $\tau_{\text {peak }}$ of rock joints. However, they cut small joints from larger ones; there is no correlation between the morphological characteristics of rock joints with different sizes.

Previous researchers have tended to focus on the shear behavior of rock joints under the constant normal loading (CNL) condition, as shown in Figure 1(a), in which case the normal stress is constant and the normal displacement of the shear boxes is servo-controlled. As a result, the distance between the upper and lower pressing plates usually increases with shear dilatancy. Though the CNL condition is generally employed for the rock joint shear tests in the laboratory, scholars have pointed out that it is only suitable for shallow rock joints because the shear dilatancy of deep rock joints is constrained by the surrounding rock. The constant normal stiffness (CNS) condition should, thus, be adopted for research (e.g., [27-29]).

Under the CNS condition (Figure 1(b)), the normal displacement of the pressing plates is linearly deformed as normal stress increases. The deformation rate is the constant normal stiffness:

$$
\sigma_{n}(t+\Delta t)=\sigma_{n}(t)+k_{n} \Delta d,
$$

where $\sigma_{n}$ is the applied normal stress on the joint specimen, $\Delta d$ it is the normal displacement of the upper pressing plate (providing the lower one is fixed) during $\Delta t$, and $k_{n}$ is the normal stiffness of the upper pressing plate.

In practice, it is very difficult to identify the $k_{n}$ value for a certain rock engineering scenario. Moreover, when the $k_{n}$ is very high, the normal displacement is small enough to be ignored. In this regard, shear tests under the CND (Constant Normal Displacement) condition can be considered as an extreme case of the CNS condition, as shown in Figure 1(c). When the normal displacement is fixed at 0 during the shear test, then the normal stiffness of the pressing plates $k_{n}=\infty$ falls under the CNS condition (Figure 1(b)). As a result, the CND condition is easier to control than the CNS condition, which usually needs a complex digital-controlled shear testing apparatus [28]. When the normal stress is loaded to the set value, the CND condition only requires fixing the normal pressing plate without changing the normal displacement according to the force on the pressing plate. This places less stringent requirements on the testing machine. Under the CND condition, the normal stress increases more significantly than under the CNS condition during shearing. This allows the extreme shear strength value of a given rock joint to be effectively obtained.

The stringent requirements for the CNS condition on the testing machine make it more difficult to control in practical experiments than the CNL condition. Few researchers have explored the scale effect of large rock joints accordingly. The primary difference between them is that the normal stress applied on the pressing plate is constant under the CNL but increases gradually under the CNS condition. As a result, the joint surface is more significantly damaged under the CNS condition. This is also related to the joint roughness (e.g., $[30,31])$. As Jiang et al. [28] stated, strain hardening behavior occurs under the CNS condition, while the initial normal stress and rock mass stiffness increase.

The stringent requirements for experimental equipment have generally prevented researchers from carrying out shear tests on large rock joints under the CNS (or CND) conditions. Additionally, there has been no previous study on the scale effect of rock joints under these conditions. In view of this, a numerical simulation method was adopted in this study. Physical shear tests under the CNL condition were implemented on concrete joint specimens, which have surface morphology to the tenth standard joint roughness profile (Table 1). Numerical tests were then conducted in PFC2D software, and the results were compared against the experimental results. On this basis, a series of numerical 


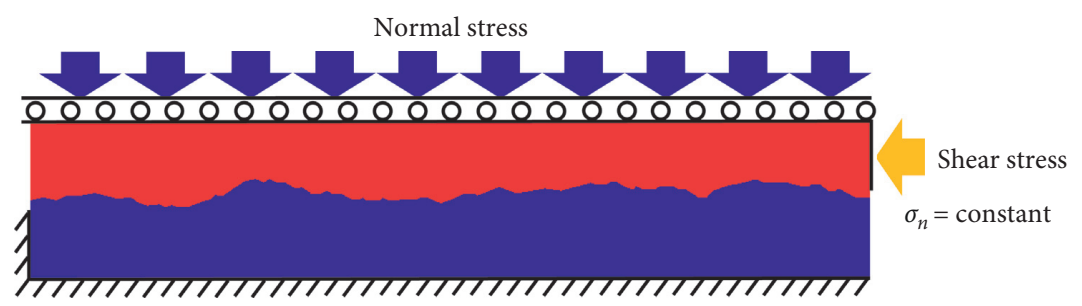

(a)

Normal stress

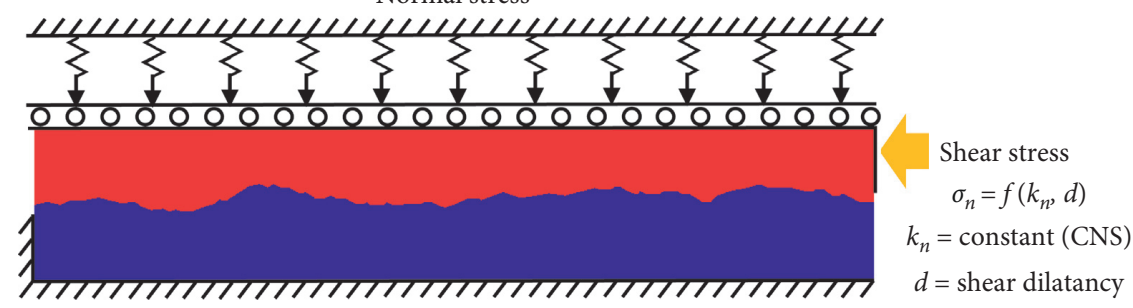

(b)

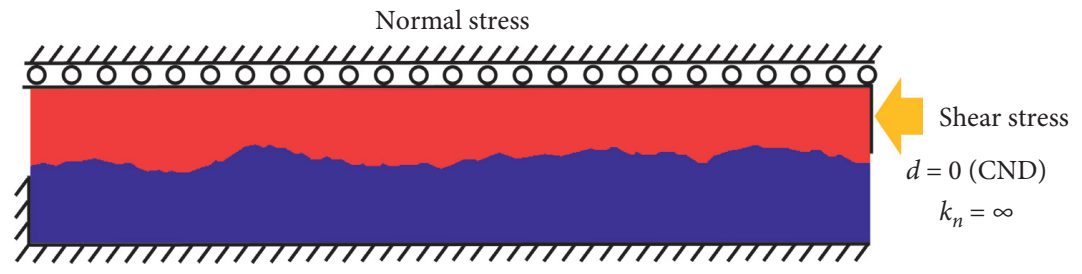

(c)

Figure 1: Shear tests under different normal loading conditions: (a) CNL. (b) CNS. (c) CND.

shear tests were employed on different-sized rock joints: $100 \mathrm{~mm}, 200 \mathrm{~mm}, 400 \mathrm{~mm}$, and $800 \mathrm{~mm}$. Large numerical rock joints were generated by enlarging and repeating the tenth standard JRC profile. The numerical shear tests were performed under both CNL and CND conditions to study the scale effect of rock joints comparatively.

\section{Physical Shear Tests and PFC2D Model Parameter Calibration}

2.1. Preparation of Artificial Rock Joint Specimens. The joint specimens were generated by pouring mortar concrete to joint moulds, which were assembled by a 3D printed joint surface of PLA material and outer metal frame (Figures 2(a) and 2(b)). With regard to the joint surface, the tenth standard JRC profile provided by Barton and Choubey [3] was selected as the basic rock joint unit in the shear direction and parallel stretched in the vertical direction. The joint size is $100 \times 100 \mathrm{~mm}^{2}$. The joint specimens and shear boxes are shown in Figure 2(c). The mass ratio of mortar concrete is sand: high-strength cement: water $=2: 6: 1$, and the mechanical parameters of the concrete material after 3 days of curing are listed in Table 2. Shear tests were conducted under the CNL condition with three different normal stresses: 10\%, 30\%, and 50\% UCS. Other relevant experimental details are shown below.

2.2. Parameter Calibration of PFC2D Models Based on Physical Test Results. Uniaxial compression and direct shear tests were used to calibrate the microproperties of PFC2D models in this study, as shown in Figure 3. The uniaxial compression test was conducted on a square specimen cured for 3 days. This specimen was fabricated with the same mechanical properties as the joint specimens (Table 2). The loading rate was $0.2 \mathrm{kN} / \mathrm{s}$ for the uniaxial compression test (Figure 3(a)).

Shear tests were conducted based on the joint specimens discussed in Section 2. During the shear tests, the lower block was fixed, and the upper block was pushed from right to left at a shear rate of $5 \mathrm{~mm} / \mathrm{min}$ (Figure 3(b)). The experimental uniaxial compression test and shear test results are shown in Figures 4 and 5, accompanied with the numerical results gathered in the PFC2D software.

The parallel-bonded model embedded in the PFC2D was adopted to simulate the concrete specimens in this study, as it realistically reflects the qualities of rock-like materials [32]. As shown in Figure 6, the bonds between two particles may break in either tension or shear directions with an associated reduction in stiffness. The parallel-bonded model can be envisioned as a set of elastic springs uniformly distributed over a rectangular cross-section with constant normal bond stiffness and shear bond stiffness lying on the contact plane and centered at the contact point $[33,34]$.

The PFC2D model requires microproperties that are carefully calibrated by physical experiments by trial-anderror. Generally, macroscopic elastic modulus $E$ depends on particle normal/shear stiffness ratio $K_{n} / K_{s}$, particle contact modulus $E_{c}$, parallel bond normal/shear stiffness ratio 


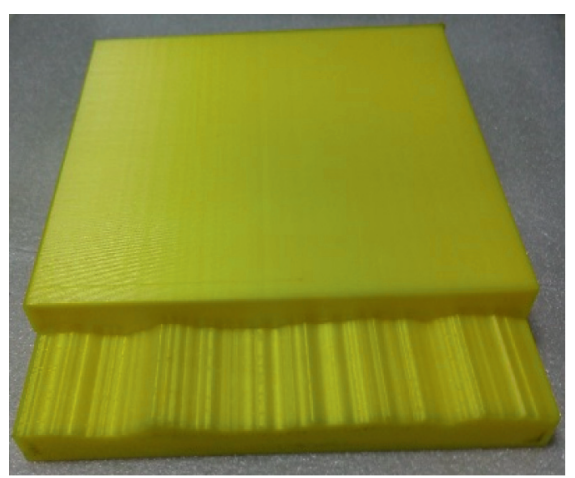

(a)

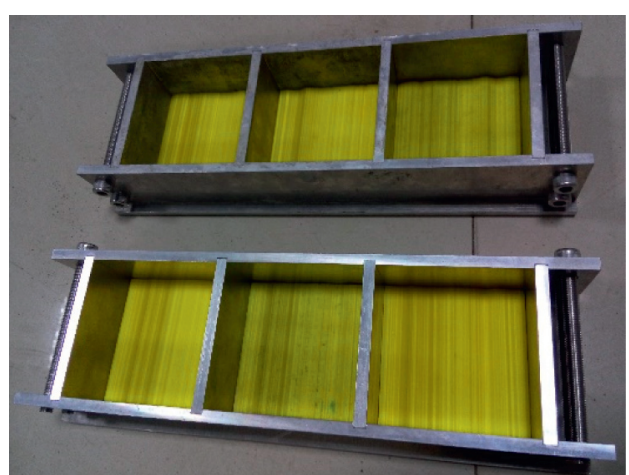

(b)

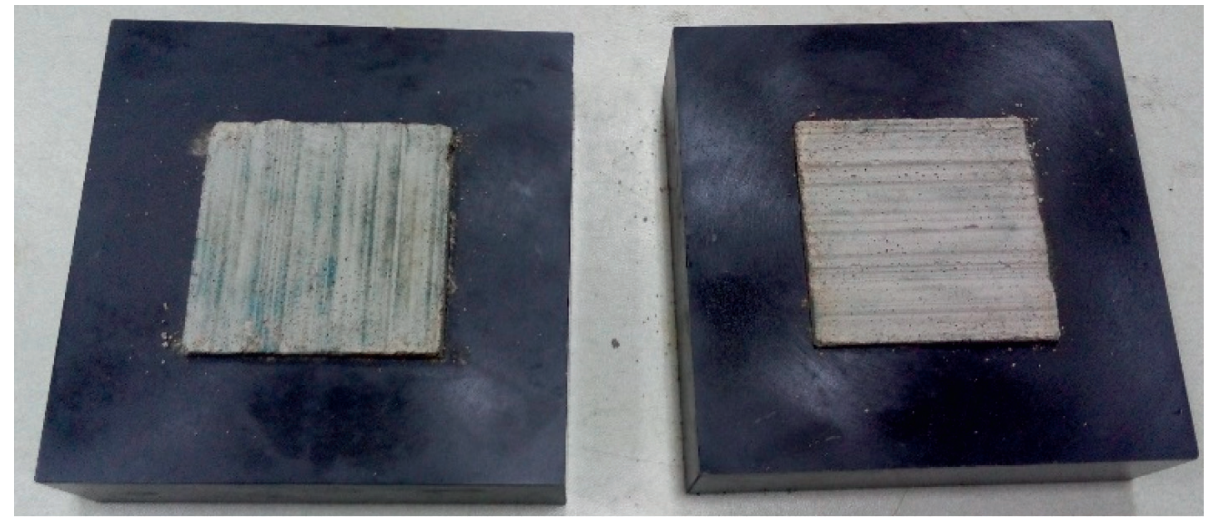

(c)

FIGURE 2: Concrete joints with uniform topography: (a) 3D printed joint surface derived from the tenth standard JRC profile [3]. (b) Assembled moulds of PLA joint surface and outer metal frame. (c) Concrete joint specimens and shear boxes.

TABLE 2: Mechanical properties of concrete specimens.

\begin{tabular}{lcccccc}
\hline $\begin{array}{l}\text { Elasticity modulus } \\
(\mathrm{GPa})\end{array}$ & $\begin{array}{c}\text { Poisson's } \\
\text { ratio }\end{array}$ & $\begin{array}{c}\text { UCS } \\
(\mathrm{MPa})\end{array}$ & $\begin{array}{c}\text { Cohesion } \\
(\mathrm{MPa})\end{array}$ & $\begin{array}{c}\text { Strength of } \\
\text { extension }\end{array}$ & $\begin{array}{c}\text { Internal frictional angle } \\
\left({ }^{\circ}\right)\end{array}$ & $\begin{array}{c}\text { Basic frictional angle } \\
\left({ }^{\circ}\right)\end{array}$ \\
\hline 12.6 & 0.22 & 24.3 & 5.34 & 1.53 & 28.6 & 32.2 \\
\hline
\end{tabular}

$\overline{K_{n}} / \overline{K_{s}}$, and parallel bond modulus $\overline{E_{c}}$. The Poisson's ratio $v$ is calibrated by altering $K_{n} / K_{s}$ and $\overline{K_{n}} / \overline{K_{s}}$, UCS is calibrated by the normal strength of parallel bonds, $\sigma_{c}$, and the shear strength of parallel bonds $\tau_{c}$, respectively. Numerical tests were carried out here under the same condition as the physical uniaxial compression and direct shear tests. The calibrated microparameters are listed in Table 3. A series of large numerical joints were generated accordingly.

\section{Numerical Shear Tests on Joints of Different Sizes and Shapes}

3.1. Geometry Design of Numerical Joints of PFC2D. In most previous studies on the scale effect of rock joints, small joint specimens were cut from larger ones (e.g., $[3,7,10,16,17,21])$ or partial replicas of a large rock joint (e.g., $[8,9,12,22]$ ). Fluctuations in the asperities on the joint surface and the dip angles of these small joints are quite different when using these methods; namely, there is no morphological correlation between small and large joints. In view of this, Ueng's [26] method was adopted in this numerical simulation; the large joint models were generated by enlarging or assembling together small ones.

The tenth standard JRC profile was selected here as a basic joint unit with length of $100 \mathrm{~mm}$, then enlarged and repeated in length to establish seven types of numerical joint model with four different lengths: $100 \mathrm{~mm}, 200 \mathrm{~mm}$, $400 \mathrm{~mm}$, and $800 \mathrm{~mm}$, all $100 \mathrm{~mm}$ in height (Figure 7). The length and height of large joint specimens were not enlarged equally according to the basic joint model, mainly for the sake of calculation efficiency. There were more than 15,000 balls for the basic joint model of $100 \mathrm{~mm} \times 100 \mathrm{~mm}$; if it was enlarged equally to achieve a joint with a length of $800 \mathrm{~mm}$, the number of balls would increase 63-fold, which is difficult for a PC to calculate.

3.2. Numerical Shear Tests under CNL Condition. During the numerical shear tests under the CNL condition, three levels of normal stresses $(10 \%, 30 \%$, and 50\% UCS) were applied on the joint specimens in a manner similar to the physical 


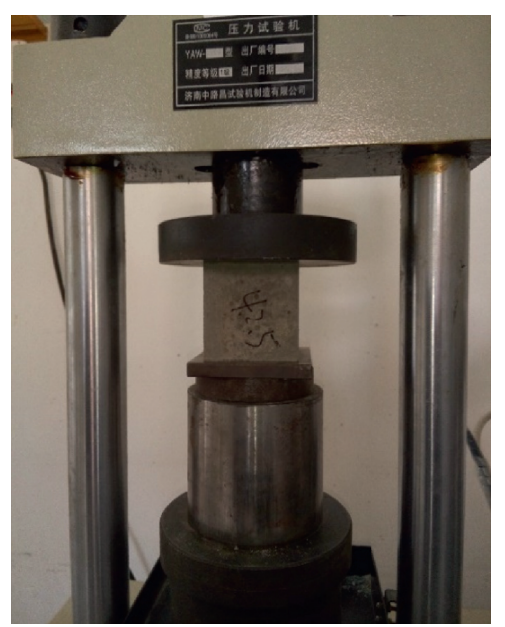

(a)

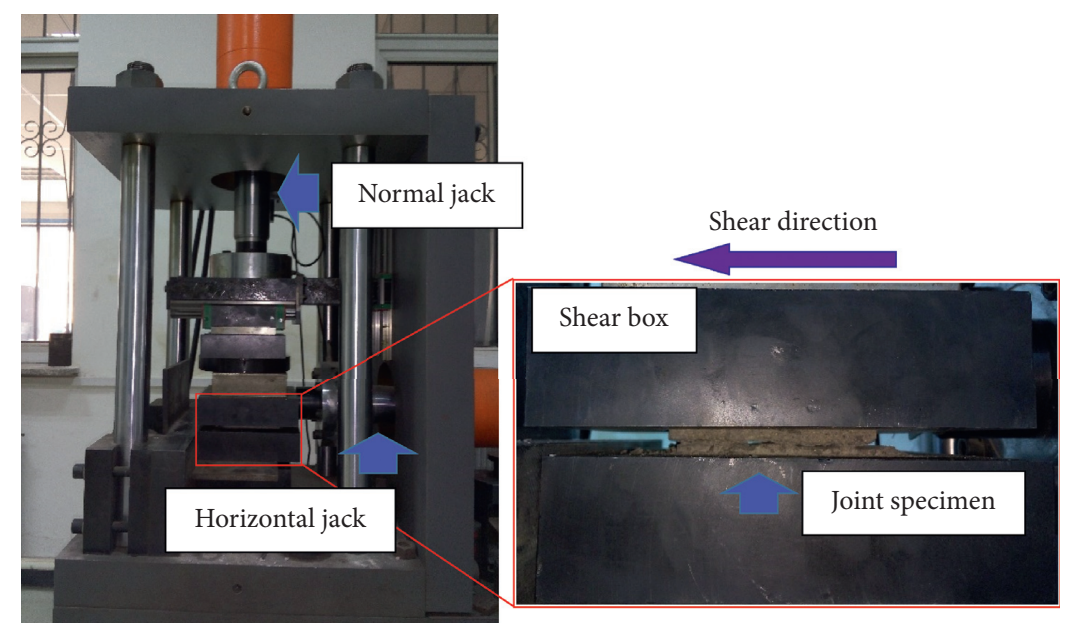

(b)

Figure 3: Uniaxial compression test and shear test of concrete material joint specimens: (a) Uniaxial compression test. (b) Shear test.

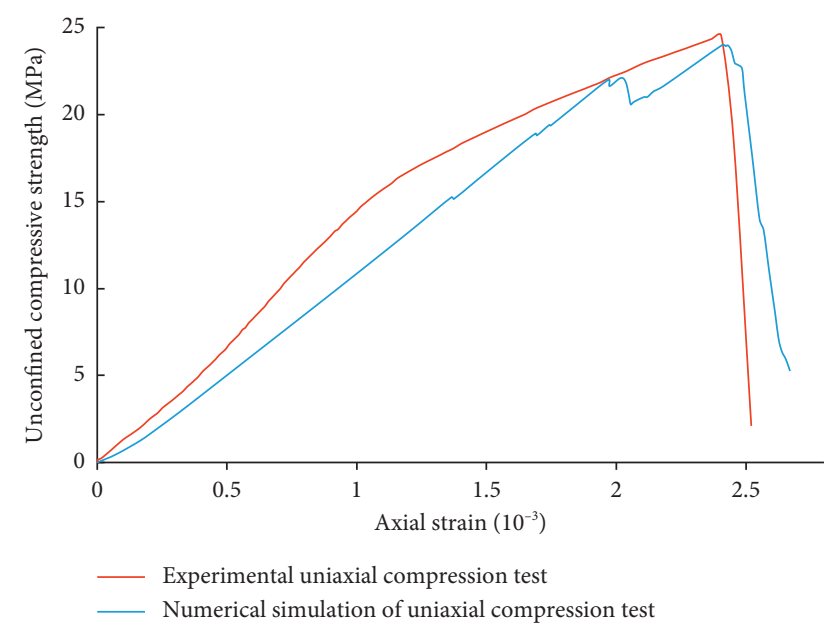

FIGURE 4: Experimental and numerical stress-strain curves of uniaxial compression tests.

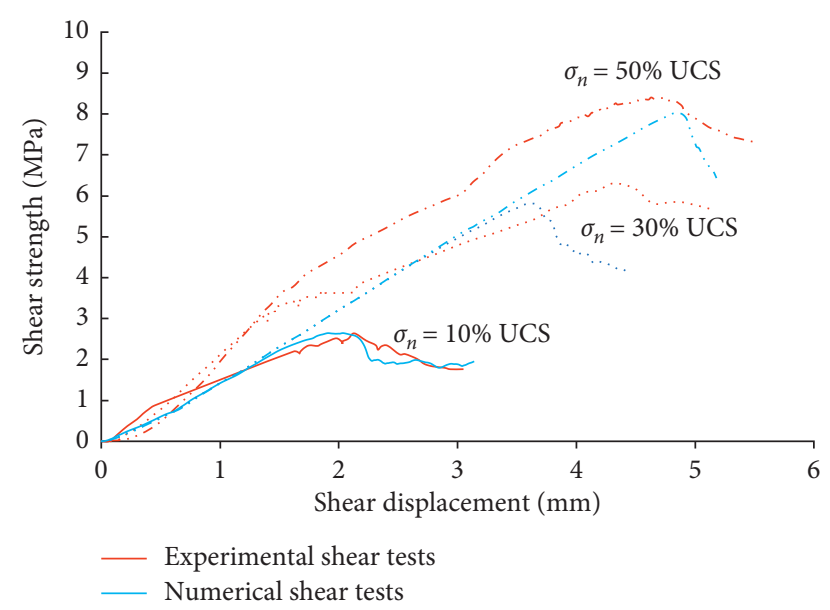

FIGURE 5: Experimental and numerical shear test results under CNL condition with three different normal stresses. shear tests. The resulting shear stress-shear displacement curves are shown in Figure 8. Generally, for both repeated and enlarged joints, the $\tau_{\text {peak }}$ value decreases as joint length increases and increases as normal stress increases. The postpeak shear strength drops rapidly for small joint specimens, showing obvious brittle failure characteristics. For larger joint specimens, the postpeak shear strength drops slowly and shows ductile failure characteristics.

In these numerical shear tests, the smooth joint model [35] was not adopted as per the stated focus on the shear resistance of asperities on the rough joint surface. The smooth joint model weakens this effect to some extent. As a result, the post $\tau_{\text {peak }}$ suddenly decreases for the small rough numerical joint, which can be attributed to the limited number of particles in contact and the fact that the size of the particles (i.e., the smallest destructible element) is much larger than that of real rock/concrete material. As shown in Figure 8 , as the joint length and the number of particles in contact increase, the post $\tau_{\text {peak }}$ tends to decrease more and more slowly. This is consistent with previous research results (e.g., $[1,6])$. Thus, the numerical shear test results are generally acceptable and can be further analyzed.

Four indexes were adopted for analysis to observe the shear behavior of the repeated and enlarged joints in detail: the peak shear strength $\tau_{\text {peak }}$, peak shear displacement $\delta_{\text {peak }}$, peak shear dilatancy displacement $d_{\text {peak }}$, and shear stiffness $k_{s}$, as shown in Figure 9. Overall, the $\tau_{\text {peak }}$ increases with normal stress but is also slightly affected by the geometrical configuration of the joints. There is little difference between the repeated and enlarged joints (Figure 9(a)).

With regard to the scale effect of $\tau_{\text {peak }}$, there was neither simple positive scale effect nor negative scale effect observed in this study under lower normal stresses (10\% or $30 \%$ UCS). Especially for the repeated joints, the $\tau_{\text {peak }}$ first rises and then falls with a maximum value at length of about $200 \mathrm{~mm}$. That is to say, no obvious scale effect occurred within a limited joint length. This agrees well with the results of Ueng's [26] experimental results. The length range of Ueng's joint 

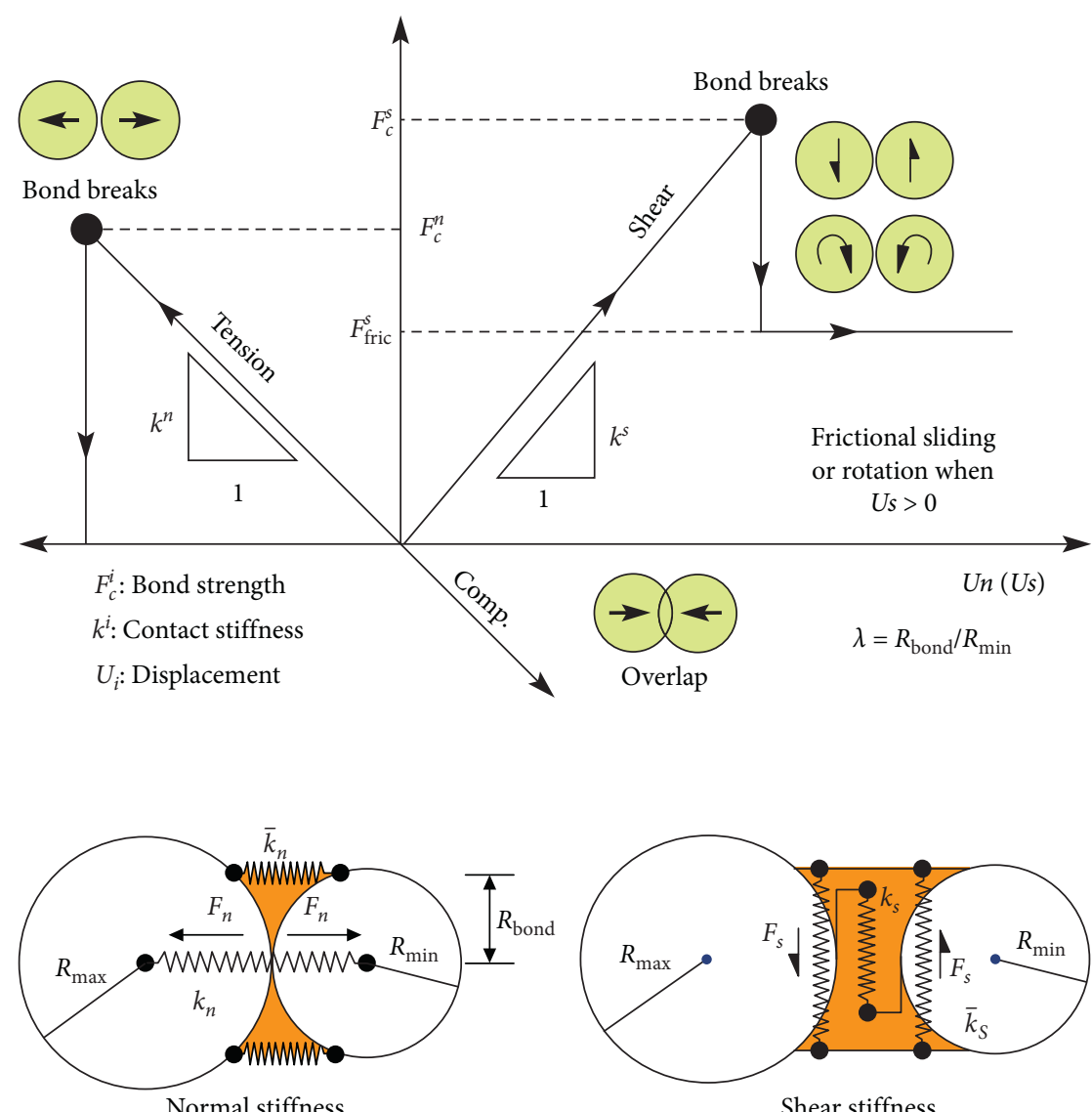

Figure 6: Microparameters and force-displacement behavior of particles in PFC2D [33], where $K_{n}$ and $K_{s}$ are normal stiffness and shear stiffness of particles, $\overline{K_{n}}$ and $\overline{K_{s}}$ are normal stiffness and shear stiffness of parallel bond, $F_{n}$ and $F_{s}$ are normal contact force and shear contact force between two particles, respectively; $R_{\text {bond }}$ is radius of parallel bond.

TABLE 3: Calibrated microparameters of PFC2D model.

\begin{tabular}{ccccccccc}
\hline & $K_{n}\left(\mathrm{~N} \cdot \mathrm{m}^{-1}\right)$ & $K_{s}\left(\mathrm{~N} \cdot \mathrm{m}^{-1}\right)$ & $\overline{K_{n}}\left(\mathrm{~N} \cdot \mathrm{m}^{-1}\right)$ & $\overline{K_{s}}\left(\mathrm{~N} \cdot \mathrm{m}^{-1}\right)$ & $\sigma_{c}(\mathrm{MPa})$ & $\tau_{c}(\mathrm{MPa})$ & $R_{\text {bond }}$ & Friction factor \\
Rock & $2.5 \times 10^{8}$ & $2.5 \times 10^{8}$ & $3 \times 10^{11}$ & $3 \times 10^{11}$ & 36 & 36 & 0.25 \\
\hline Joint & 0 & 0 & 0 & 0 & 0 & 0 & 0 & 0.1 \\
\hline
\end{tabular}

specimens was from $100 \mathrm{~mm}$ to $300 \mathrm{~mm}$, and the experimental material ranged from $9.0 \mathrm{MPa}$ for a specimen of $54 \mathrm{~mm}$ in diameter to $6.8 \mathrm{MPa}$ for a specimen of $162 \mathrm{~mm}$ in diameter; the normal stresses applied on the joint specimens in their shear tests were only $0.294 \mathrm{MPa}$ to $0.882 \mathrm{MPa}$.

As shown in Figure 9(a), the $\tau_{\text {peak }} s$ decreased with the increase in joint length on the whole, which is consistent with the statements of most previous scholars as well. Even so, because the scale effect of $\tau_{\text {peak }}$ was unstable, fluctuated within a limited range of joint size, and affected by the normal stress and surface morphology, and the negative scale effect of $\tau_{\text {peak }}$ was only obvious when the joint reached a sufficient length. This may be the main reason why different conclusions were drawn by previous scholars.

The peak shear displacement $\delta_{\text {peak }}$ is the horizonal dislocation distance of the two halves of shear boxes at $\tau_{\text {peak }}$, as illustrated in Figure 9(b). The $\delta_{\text {peak }}$ peak shear displacement increased as joint length increased for both the repeated and enlarged joints. Moreover, it was more significant for the enlarged joints under higher normal stress (50\% UCS). On the contrary, the peak shear dilatancy displacement $d_{\text {peak }}$ (which is equal to the shear dilatancy displacement at $\tau_{\text {peak }}$ ) was more significant under lower normal stress (10\% and 30\% UCS), as shown in Figure $9(\mathrm{c})$. There was a slight increase in $d_{\text {peak }}$ observed for the repeated joints with increase in joint length, but with an obvious increase for the enlarged joints, especially under lower normal stress (10\% and 30\% UCS). Substantial "waviness" on the joint surface was shorn off under higher normal stress (50\% UCS), which created a small $d_{\text {peak }}$ for the enlarged rock joints.

The shear stiffness $k_{s}$ is another important index, which represents the slope of the prepeak portion of the shear stress versus shear displacement graph, as shown in Figure $9(\mathrm{~d})$. The $k_{s}$ in this test decreased with the increase in joint length due to the lower $\tau_{\text {peak }}$ and higher $\delta_{\text {peak }}$ of the large joints. There was little difference between the repeated and enlarged joints, which indicates that the $k_{s}$ is only related to the mechanical properties of the joint surface. 

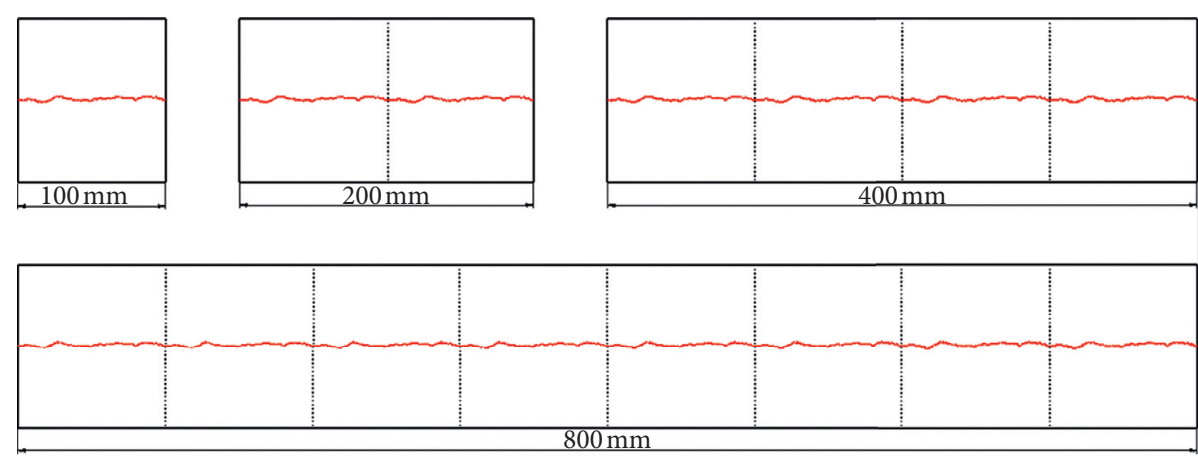

(a)
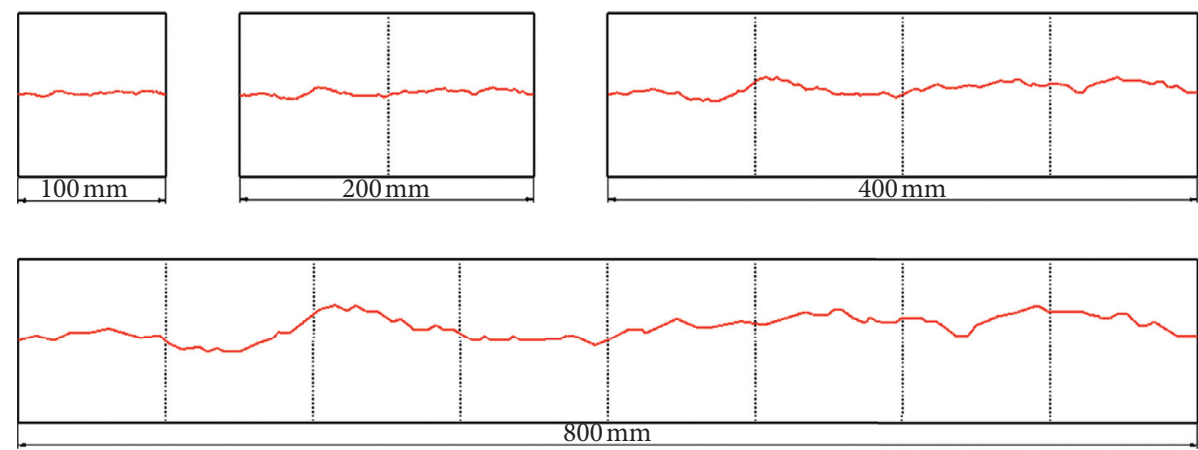

(b)

FIGURE 7: Geometry design of numerical joints in PFC2D: (a) repeated and (b) enlarged rock joints derived from the tenth standard JRC profile.

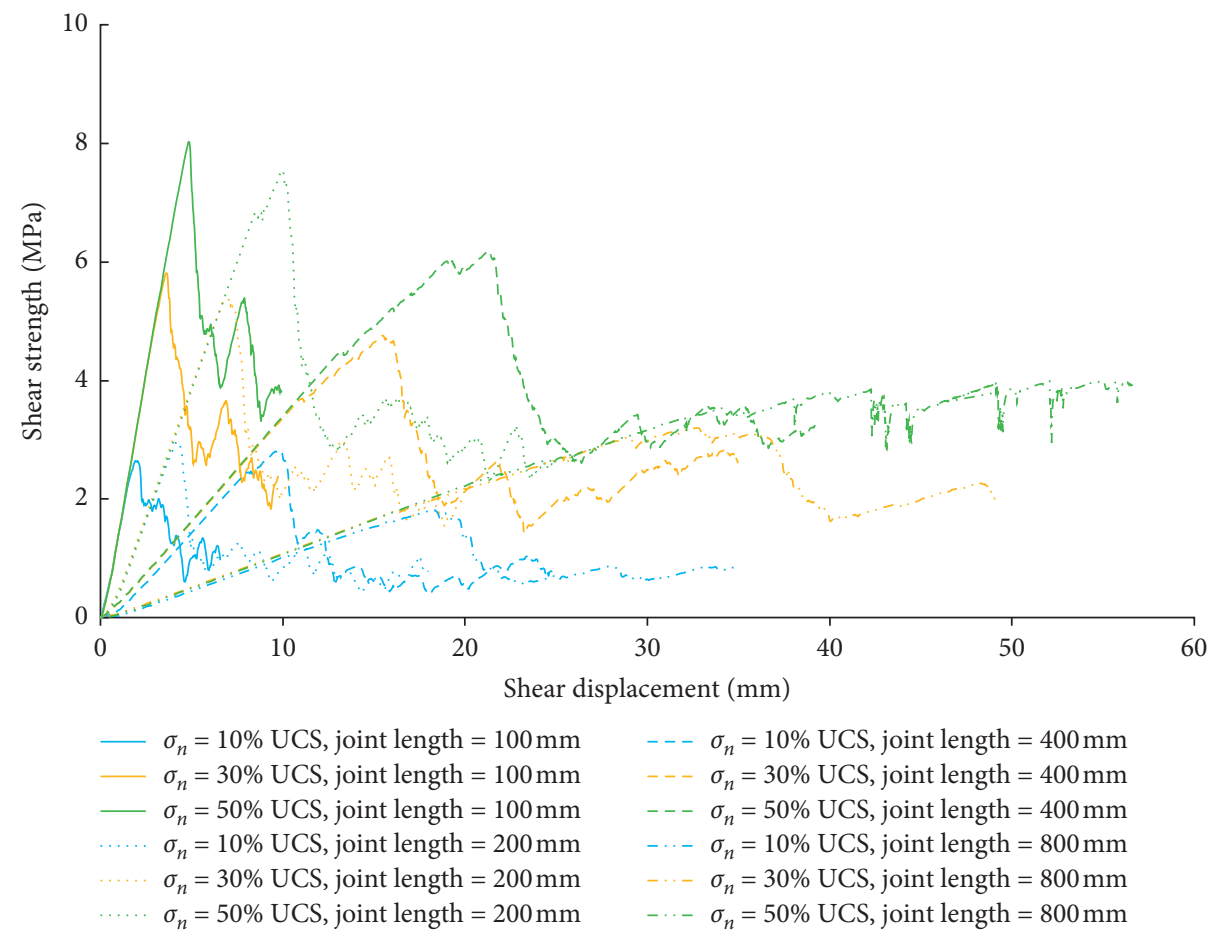

(a)

Figure 8: Continued. 


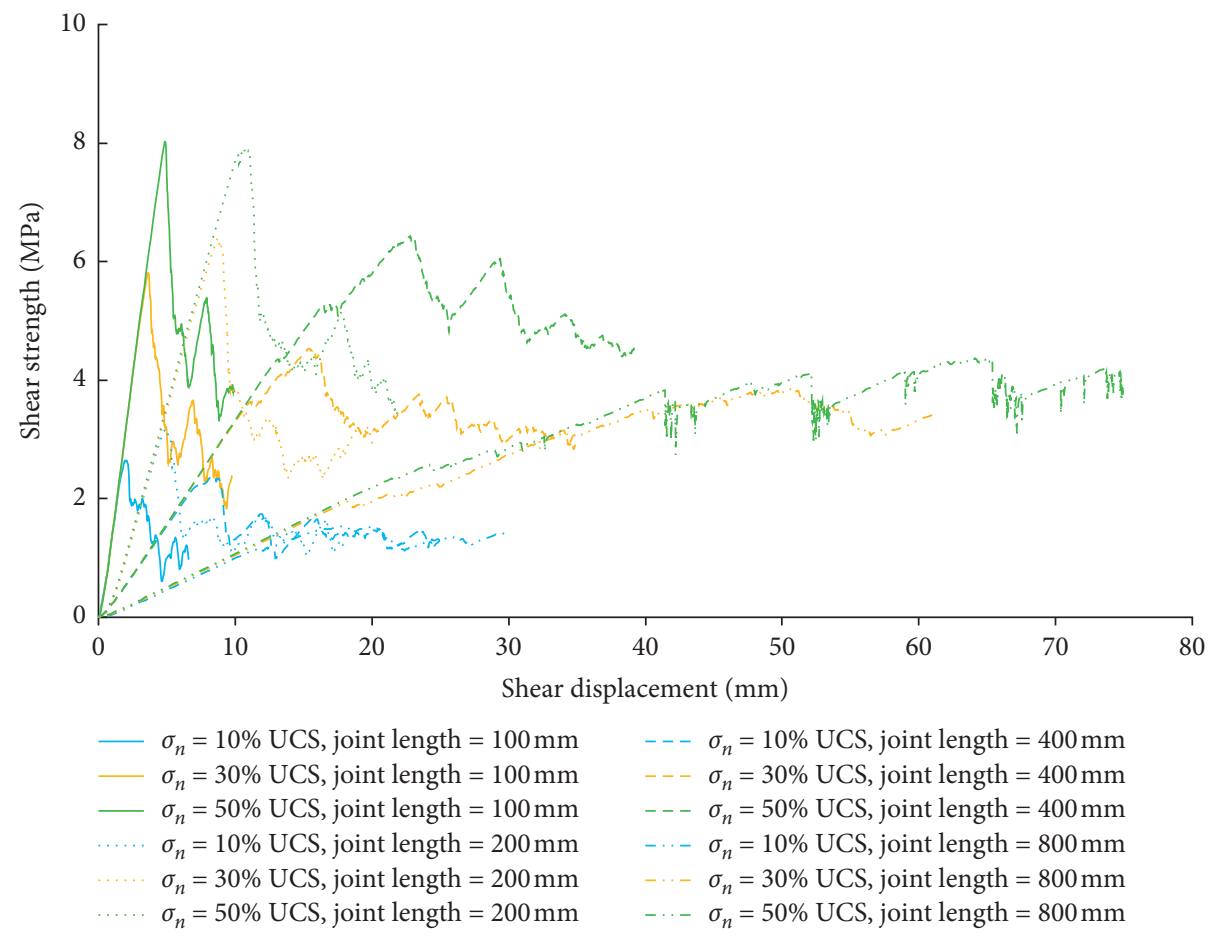

(b)

Figure 8: Shear stress-shear displacement curves of different-sized rock joints under CNL condition: (a) repeated and (b) enlarged rock joints derived from tenth standard JRC profile.

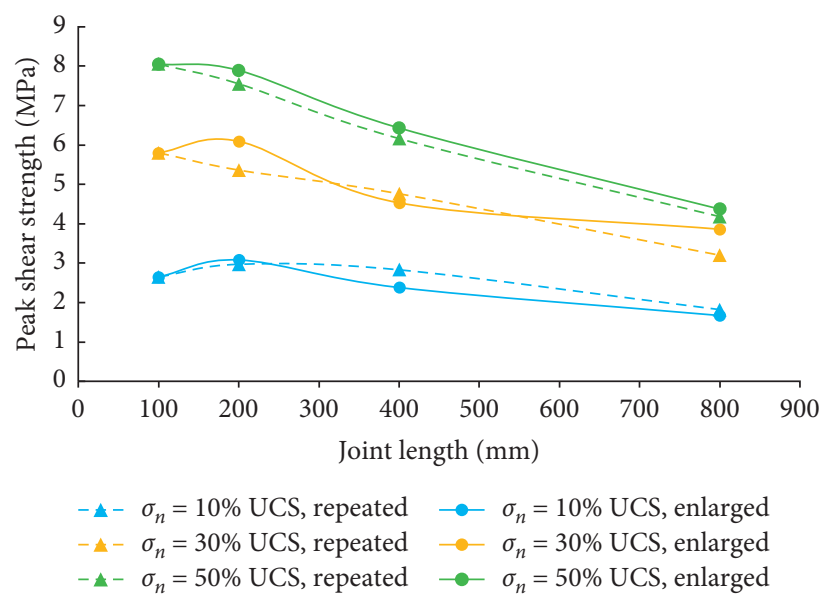

(a)

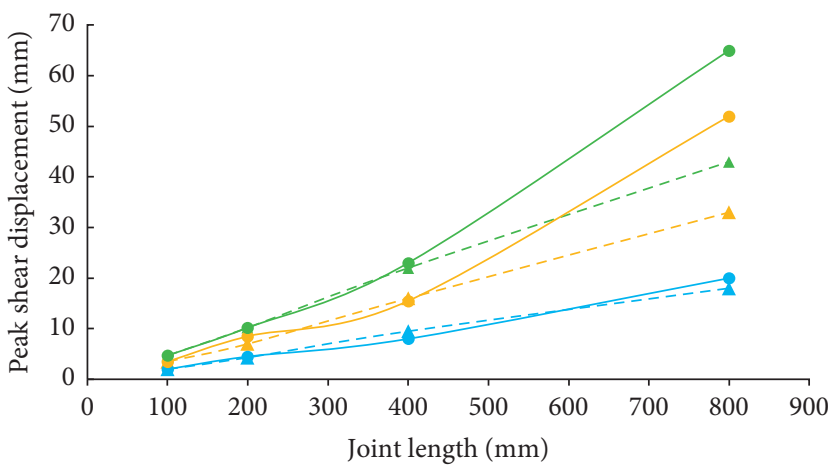

$-\sigma_{n}=10 \%$ UCS, repeated $\longrightarrow \sigma_{n}=10 \%$ UCS, enlarged

$-\sigma_{n}=30 \%$ UCS, repeated $\longrightarrow \sigma_{n}=30 \%$ UCS, enlarged

$-\sigma_{n}=50 \%$ UCS, repeated $\rightarrow \sigma_{n}=50 \%$ UCS, enlarged

(b)

FIgURE 9: Continued 


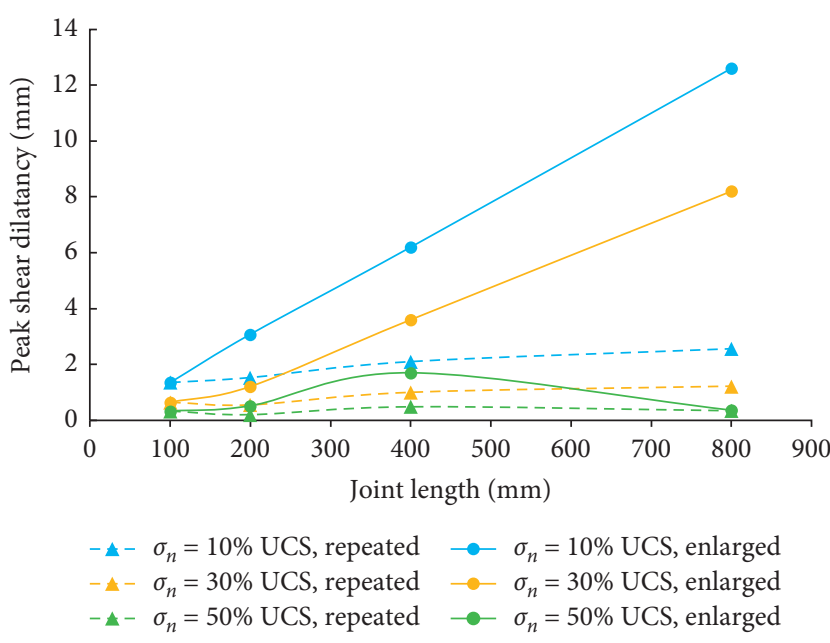

(c)

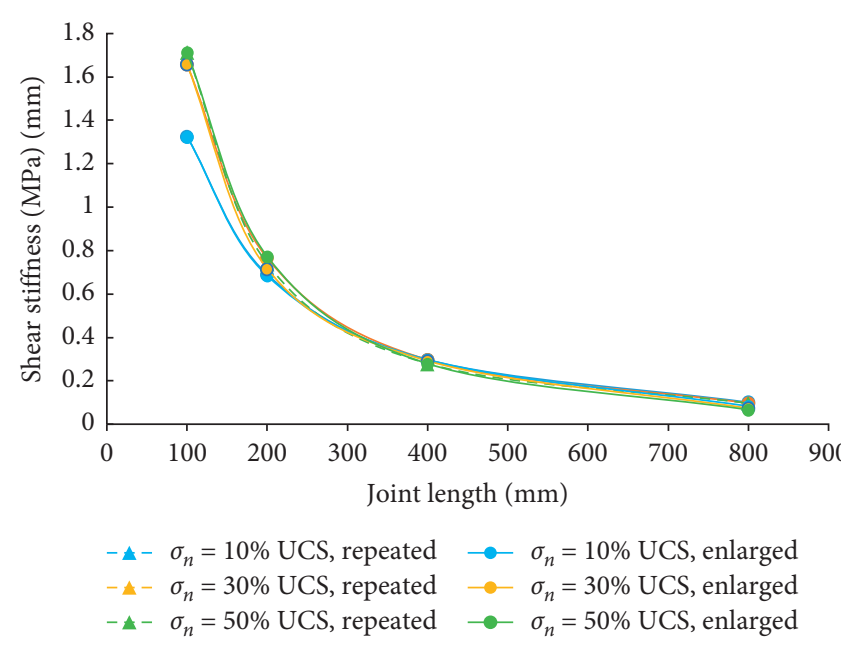

(d)

Figure 9: Shear behavior of different-sized repeated and enlarged joints under CNL condition. (a) Peak shear strength. (b) Peak shear displacement. (c) Peak shear dilatancy displacement. (d) Shear stiffness.

\subsection{Numerical Shear Tests under CND Condition. Similar to} the shear tests under the CNL condition, three levels of normal stress $(10 \%, 30 \%$, and $50 \%$ UCS) were adopted in the shear tests under the CND condition with the shear dilatancy displacement fixed to 0 . The shear stress-shear displacement curves are shown in Figure 10. The overall trend of these results is similar to that under the CNL condition (Figure 8). For in-depth analysis, four indexes are used for comparison: $\tau_{\text {peak }}, \delta_{\text {peak }}, k_{s}$, and the percentage of the normal stress increment $\omega$.

Unlike the shear test results under CNL condition, there was a significant difference in $\tau_{\text {peak }}$ between the repeated and enlarged rock joints under the CND condition (Figure 11(a)). The $\tau_{\text {peak }} s$ of the enlarged joints were apparently higher than those of the repeated joints under lower normal stresses (10\% and 30\% UCS), but with the increase in normal stress, the gap between the two kinds of joints gradually decreased. Under the CND condition, the $\tau_{\text {peak }}$ showed neither simple positive scale effect nor negative scale effect. With increase in joint length, the $\tau_{\text {peak }}$ first increased, then decreased for the enlarged joints under any normal stress. This phenomenon was less significant for the repeated joints, which showed an overall negative scale effect. Thus, the $\tau_{\text {peak }}$ is significantly affected by the geometrical configuration of a joint under the CND condition, in which case the influence of substantial fluctuations on the joint surface is more prominent.

The above numerical results are similar to those of Ueng's experimental results [26] under the CNL condition; that is, the $\tau_{\text {peak }}$ of enlarged rock joints may first increase and then decrease in the range of $100 \mathrm{~mm}$ to $300 \mathrm{~mm}$, but the CND loading conditions highlight this change trend. The main reason for this may be that joints with large fluctuations provide greater shear resistance, which leads to a positive scale effect on the $\tau_{\text {peak }}$ over a limited length range. However, when the joints are too long, these large fluctuations on the joint surface do not form any resultant force against the shear direction; thus, they are sheared in turn, and there is no obvious peak shear strength (Figure 10).
The peak shear displacement $\delta_{\text {peak }}$ (Figure 11(b)) increased with the increase in joint length for both repeated and enlarged joints under the CND condition. This is similar to the results under the CNL condition. In general, the $\delta_{\text {peak }} s$ of enlarged joints were larger than those of the repeated ones under lower normal stresses (30\% and 50\% UCS), especially for the large joints, but there was little difference under higher normal stress (50\% UCS). The similar effects are also reflected in the percentage of normal stress increment $\omega$ shown in Figure 11(c). Both repeated and enlarged joints achieved a larger $\omega$ value under low normal stress $(10 \%$ UCS), and the enlarged joints increased to greater extent than the repeated ones. With the increase in normal stress, the $\omega$ tended to decrease for both joint types, as did the gap between them. Combined with the experimental results under the CNL condition, this indicates that the shear tests under the CNL and CND conditions are consistent when the normal stress is sufficiently high.

Under the CND condition, the shear stiffness $k_{s}$ still decreased with increasing joint length as shown in Figure 11(d). Despite some small fluctuations, the change tendency of $k_{s}$ was almost the same as that under the CNL condition. Therefore, the shear stiffness $k_{s}$ seems to be less sensitive to the loading conditions (CNL or CND), while the joint length is a key factor in $k_{s}$.

3.4. Comparison of Shear Tests under CNL and CND Conditions. As stated above, the CND condition can be considered as an extreme case of the CNS condition, under which the shear dilatancy displacement is strictly restricted to 0 during shearing. Thus, the normal stress increases more significantly under the CND condition, especially for joints with large fluctuations under low original normal stress. The percentage of $\tau_{\text {peak }}$ increment under the CND condition compared to the CNL condition is shown in Figure 12, where $\tau_{\text {peak }}$ increases more for the 

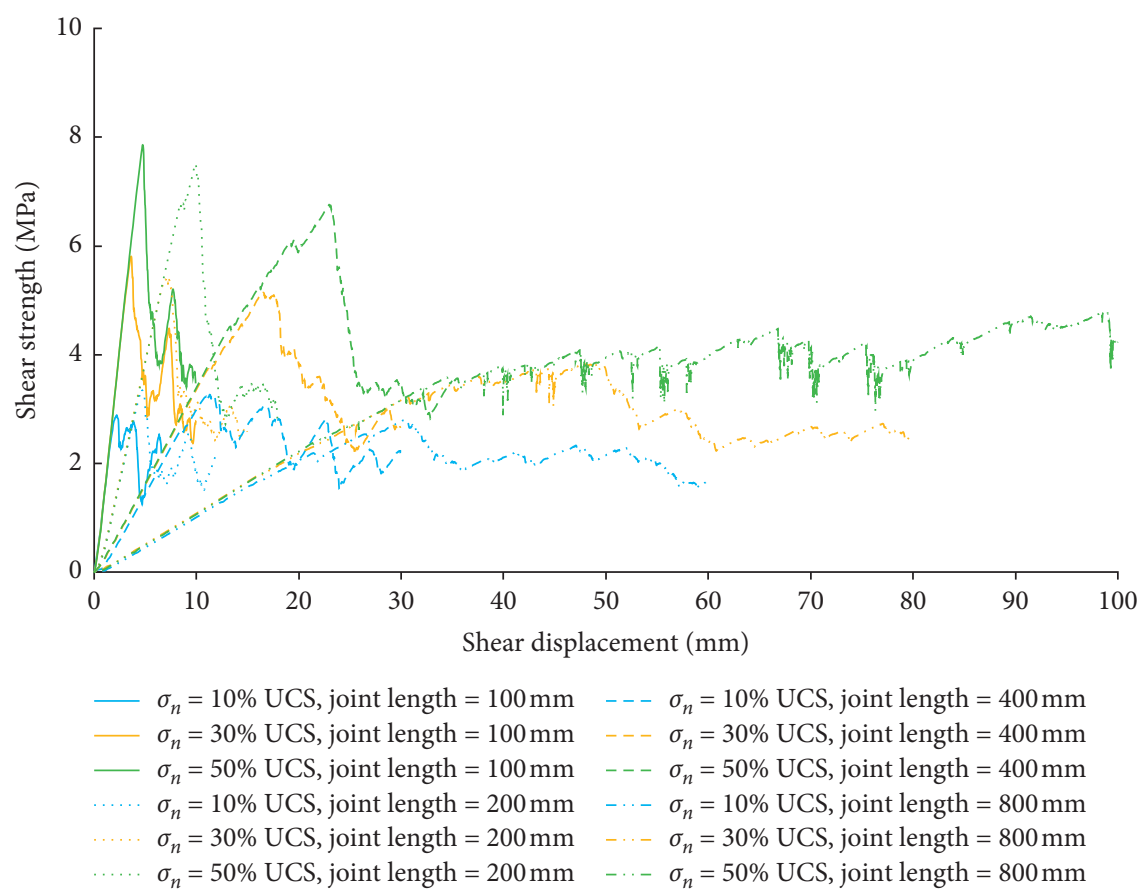

(a)

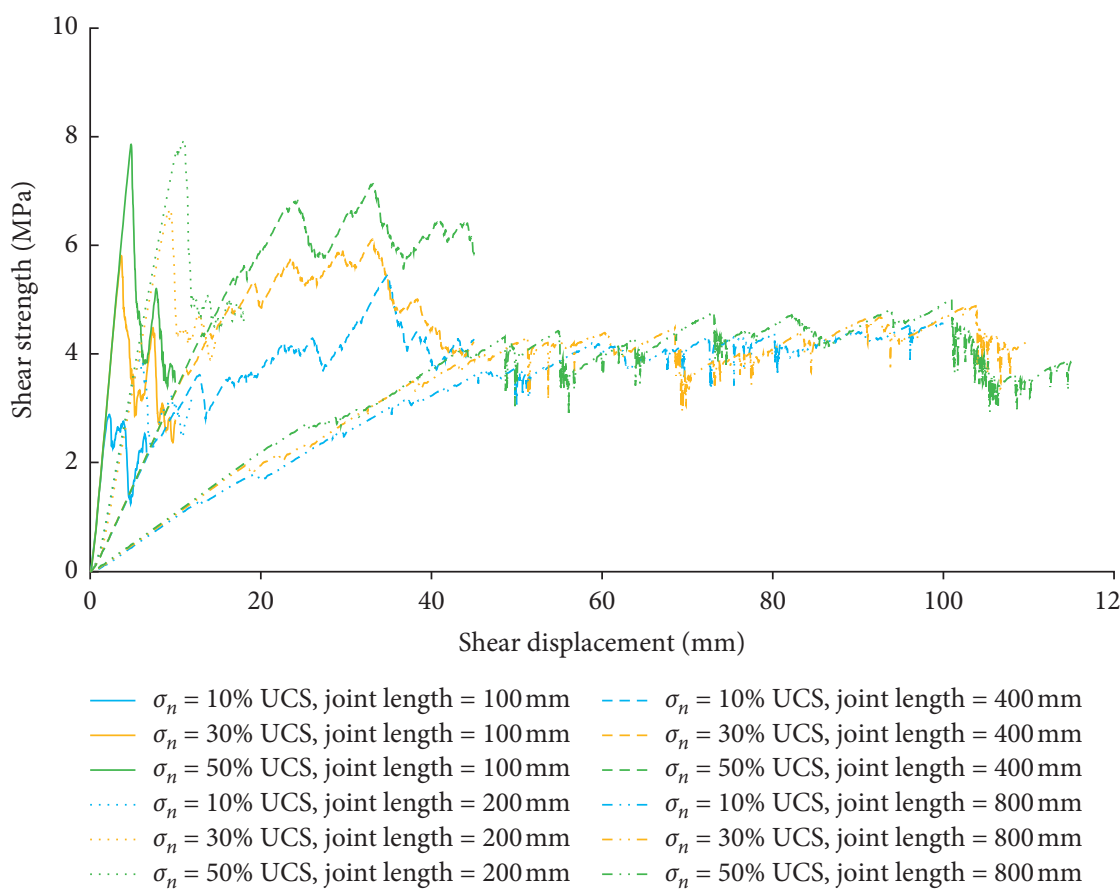

(b)

Figure 10: Shear stress-shear displacement curves of different-sized rock joints under CND condition: (a) repeated and (b) enlarged rock joints derive from the tenth standard JRC profile.

enlarged joints than the repeated ones. However, the difference between the two kinds of joints appears to decrease significantly with increase in normal stress. This is because shear dilatancy is very small under high normal stress for both repeated and enlarged joints. Compared to the $\tau_{\text {peak }}$ under the CNL condition, the percentage of $\tau_{\text {peak }}$ increment under the CND condition is positively correlated with joint length, for both repeated joints or enlarged joints.

As shown in Figure 12, the peak shear strength increment was slightly negative for short joint specimens under the normal stress of 50\% UCS, which actually reflects that the CND and CNL loading conditions are very similar under high normal stress. This is further reflected in the limited 


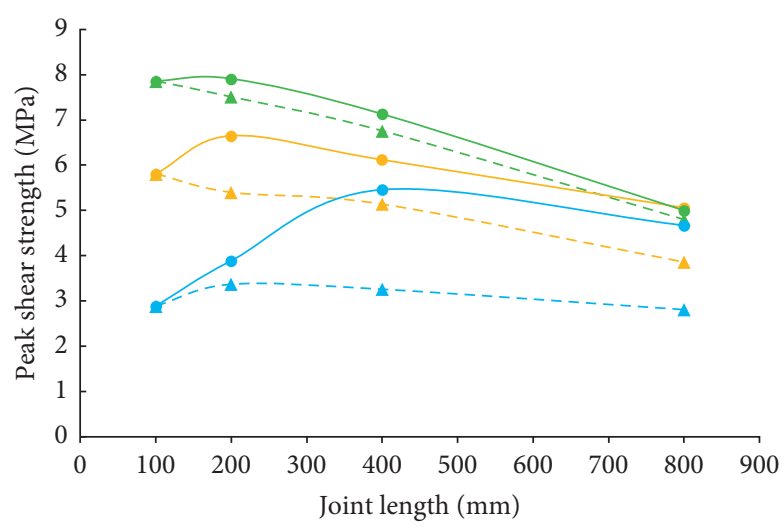

$-\sigma_{n}=10 \%$ UCS, repeated $--\sigma_{n}=10 \%$ UCS, enlarged $-\sigma_{n}=30 \% \mathrm{UCS}$, repeated $\longrightarrow \sigma_{n}=30 \% \mathrm{UCS}$, enlarged $-\sigma_{n}=50 \%$ UCS, repeated $--\sigma_{n}=50 \%$ UCS, enlarged

(a)

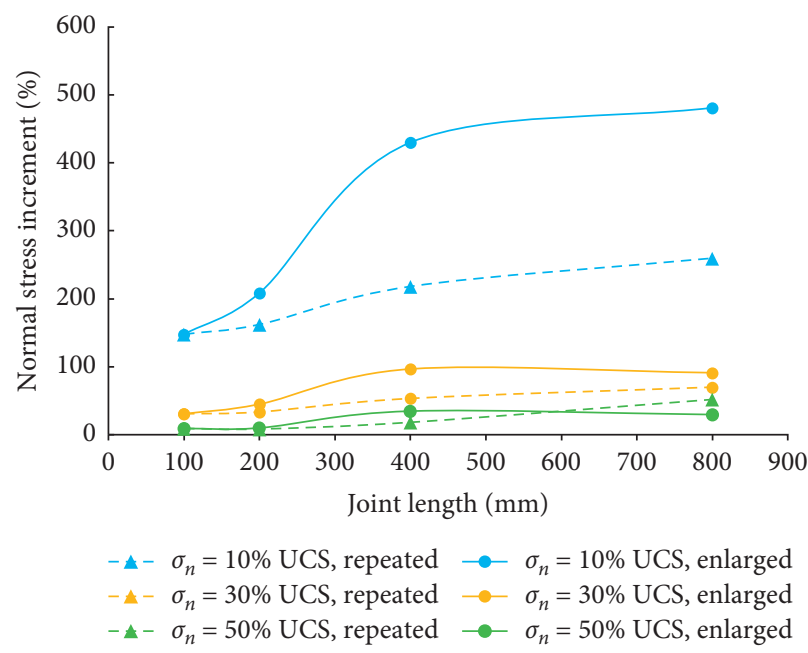

(c)

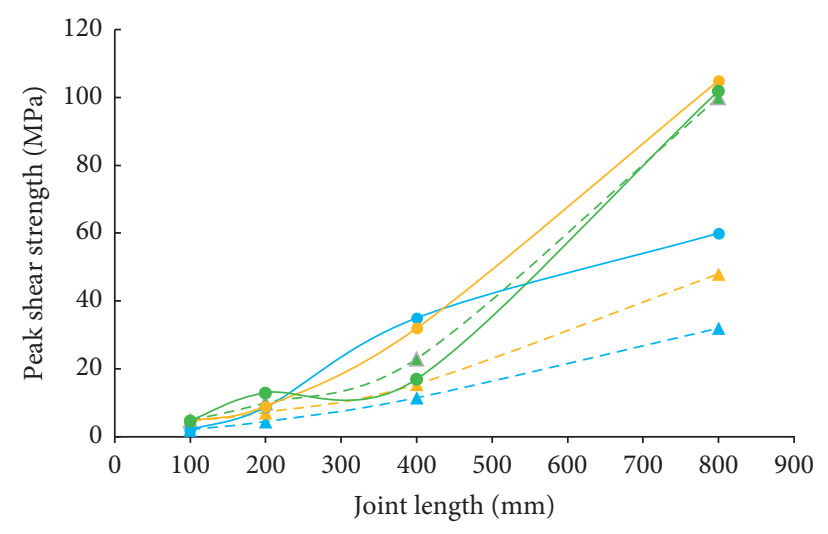

$-\sigma_{n}=10 \% \mathrm{UCS}$, repeated $\longrightarrow \sigma_{n}=10 \% \mathrm{UCS}$, enlarged $-\sigma_{n}=30 \%$ UCS, repeated $\longrightarrow \sigma_{n}=30 \%$ UCS, enlarged $-\sigma_{n}=50 \%$ UCS, repeated $\longrightarrow \sigma_{n}=50 \%$ UCS, enlarged

(b)

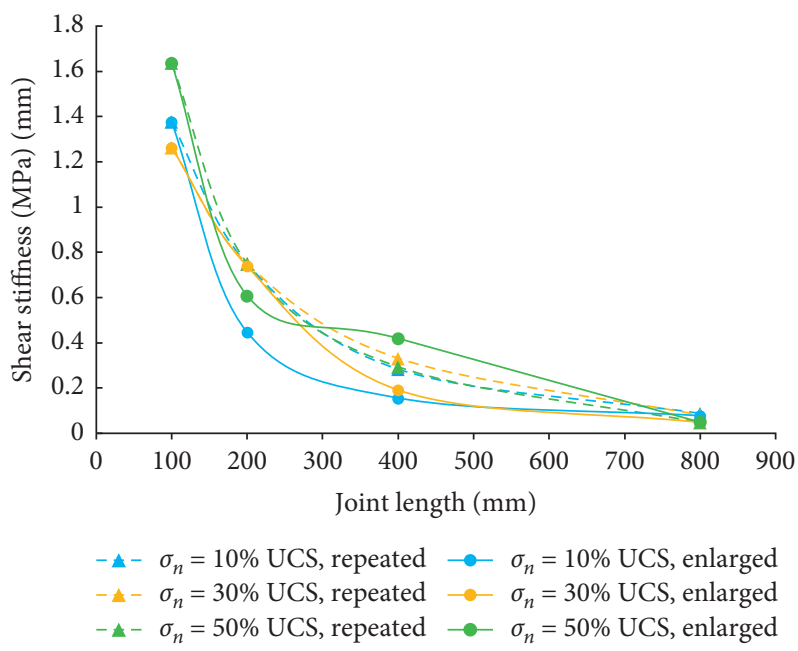

(d)

Figure 11: Shear behavior of different-sized repeated and enlarged joints under CND condition. (a) Peak shear strength. (b) Peak shear displacement. (c) Normal stress increment. (d) Shear stiffness.

normal stress increment shown in Figure 11(c). The slight difference or negative value of the shear strength increment belongs to the normal fluctuation of the numerical calculation results. For longer joints, the stress concentration at the edge of the specimen created a significant increase in normal stress resulting in a larger increase in peak shear strength, as shown in Figure 13.

The maximum principal stress contours of the repeated and enlarged joints under different normal stresses $(10 \%$ and $50 \%$ UCS) are shown in Figure 13. Only the results under the $\mathrm{CNL}$ condition are provided here, as the main difference between the two conditions (CNL and CND) was the effective normal stress during the shear tests; they were almost the same under high normal stress. The maximum principal stress contours show where the contact area increased with increase in joint length, especially for the repeated joints under lower normal stress (Figures 13(a) and 13(c)), though the maximum principal stress was higher in the contact areas of the large joint. They were distributed relatively evenly on the joint surface, which may have caused the negative scale effect of $\tau_{\text {peak }}$. In addition, the stress distribution of the large-scale joint specimen is not uniform. A severe stress concentration emerged in the face of the shear box even resulting in damage under high stress (Figures 13(b) and 13(d)). Thus, for a large rock joint, the shear resistance tends to be mainly borne by the joint ends during the shear process.

\section{Discussion}

The CNL and CNS conditions, respectively, represent shallow and underground rock joints. The essential difference between them is how the shear dilatancy is restricted. In extreme cases of the CNS loading condition, that is, where the stiffness of the normal pressing plate is infinite and shear dilatancy is completely restricted during the shear process, the CND condition is achieved. Thus, the CND loading condition is an extreme case of the CNS. The minimum and maximum $\tau_{\text {peak }} s$ of a joint under a certain normal stress can be obtained under the CNL and CND 


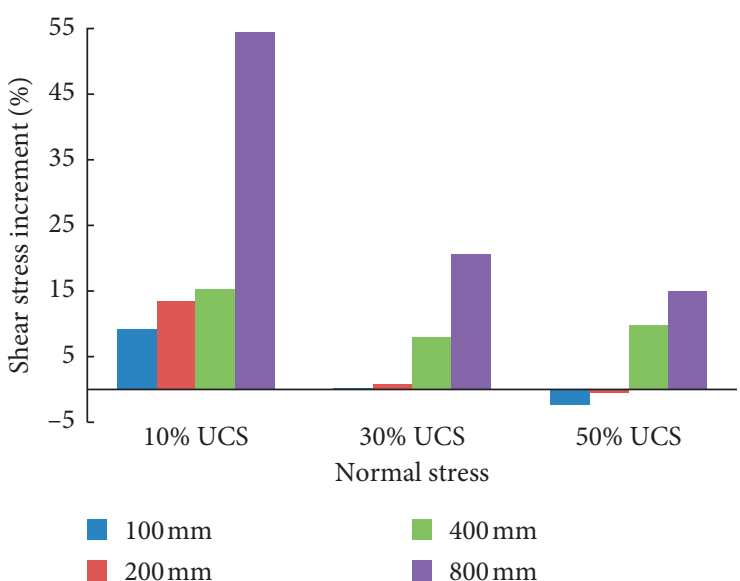

(a)

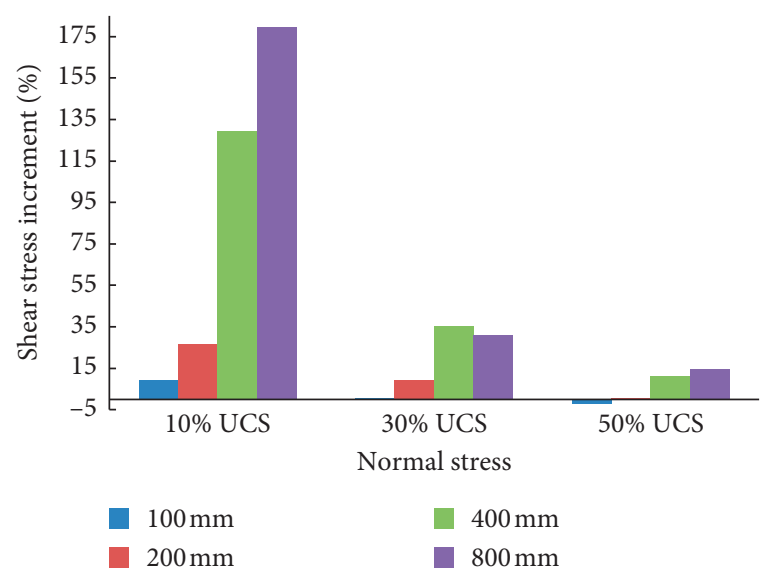

(b)

FIGURE 12: Shear stress increment under CND condition compared to CNL condition. (a) Repeated rock joints. (b) Enlarged rock joints.
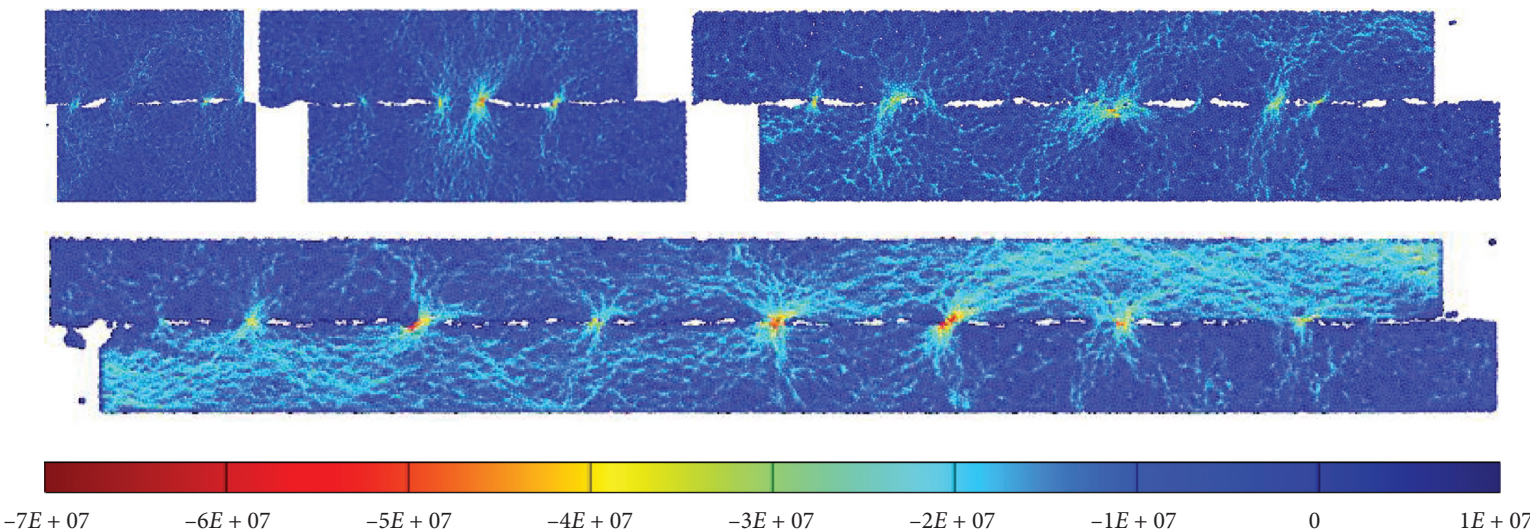

(a)
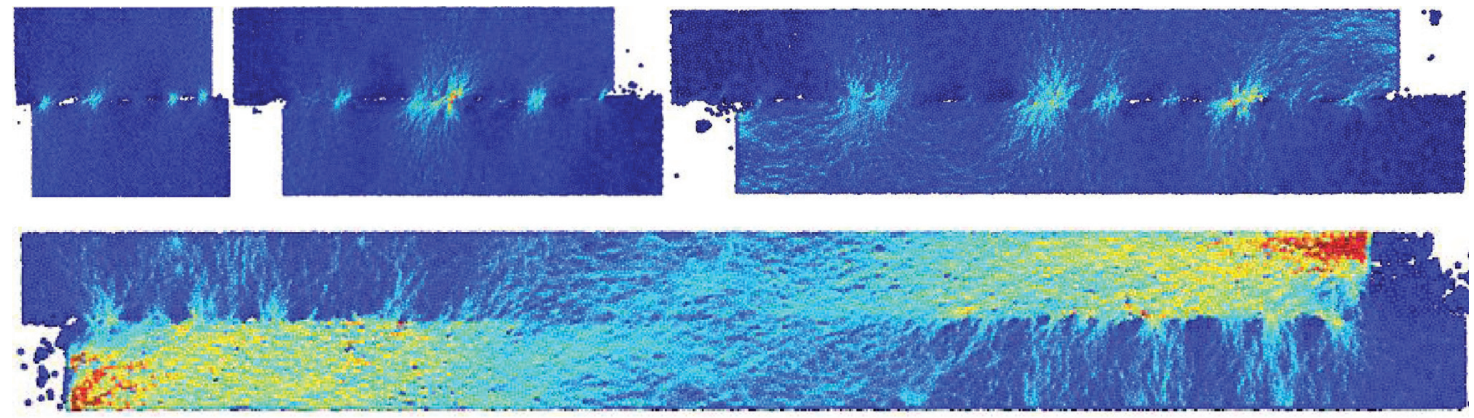

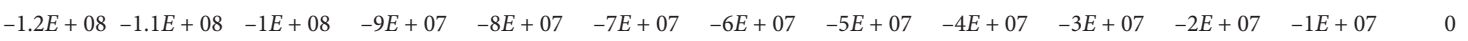

(b)

Figure 13: Continued. 

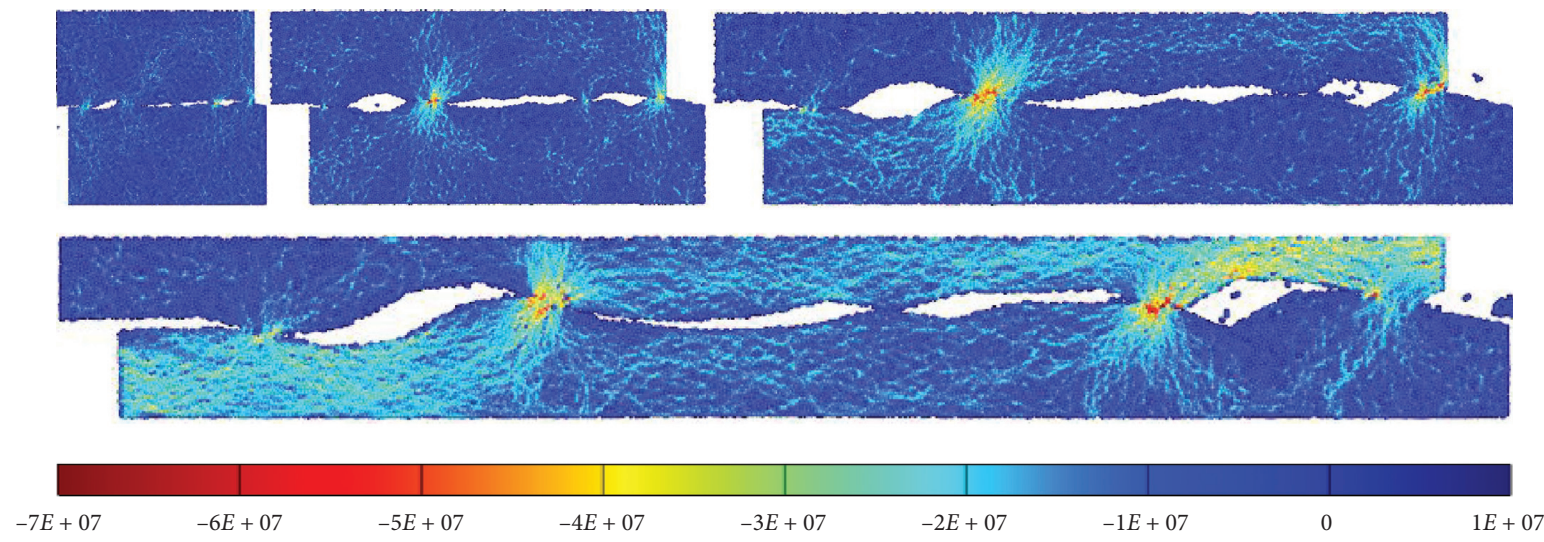

(c)
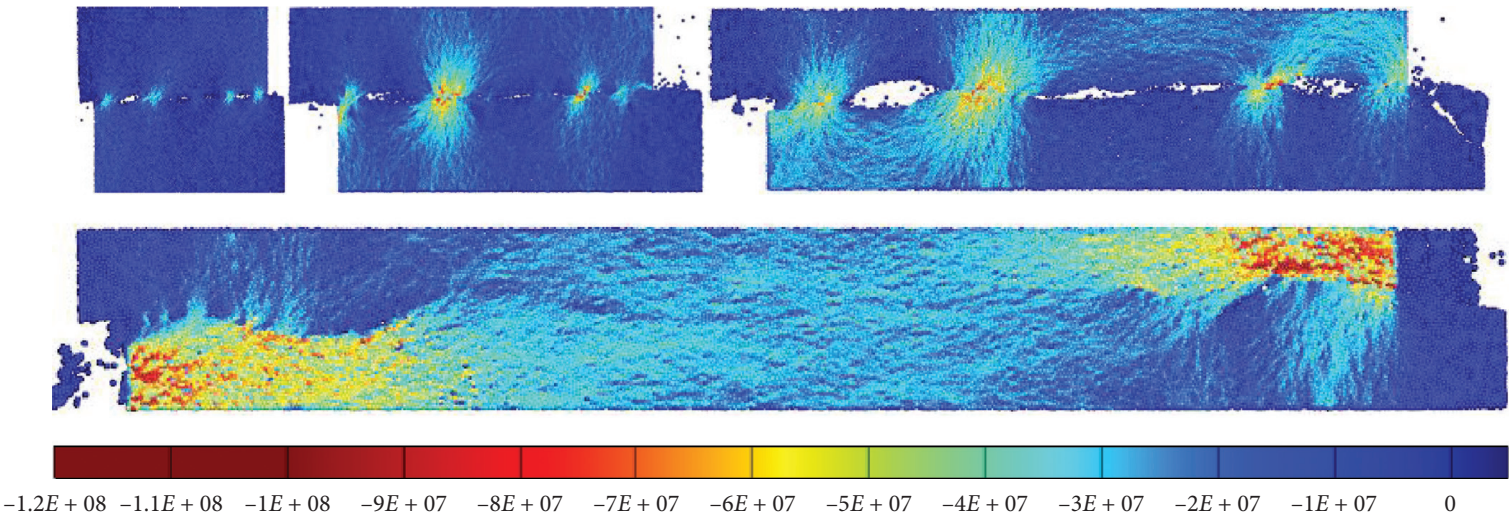

(d)

FIGURE 13: Maximum principal stress for repeated and enlarged joints in shear tests under CNL condition. (a) Repeated joints sheared under normal stress of $10 \%$ UCS. (b) Repeated joints sheared under normal stress of 50\% UCS. (c) Enlarged joints sheared under normal stress of $10 \%$ UCS. (d) Enlarged joints sheared under normal stress of 50\% UCS.

conditions, and the CNS condition can be regarded as a special case between them. From this perspective, the physical shear tests under the CND condition merit further study. Its requirements on the testing system are much lower than those of the CNS condition.

According to the numerical shear tests conducted in this study, although $\tau_{\text {peak }}$ showed a negative scale effect in a large range of joint sizes, positive scale effect or no scale effect can also be observed in a narrow joint length range. Therefore, it is reasonable that previous scholars reached different conclusions on this issue. For a series of joints with different surface morphology, the results of this study show that the maximum $\tau_{\text {peak }}$ can be obtained from joints with a length of about $100 \mathrm{~mm}$ to $400 \mathrm{~mm}$. The length required for the enlarged joints is even longer, especially for the CND condition with lower original normal stress (Figure 11(a)). Larger joint specimens are needed to study the scale effect of $\tau_{\text {peak }}$; $400 \mathrm{~mm}$ seems to be the minimum size requirement, lest altogether unstable experimental results follow.

\section{Conclusion}

In this study, numerical shear tests were performed on a series of repeated and enlarged joints under CNL and CND conditions, respectively. The numerical joint models were established in PFC2D software, and the microparameters were calibrated based on uniaxial compression and shear tests on physical concrete specimens. The numerical shear tests greatly expanded the joint size and loading condition of the physical shear tests and revealed important insights into the scale effect of rock joints.

The numerical shear test results show that the shear stress-shear displacement curves change from brittle failure to ductile failure with increase in joint length. The $\tau_{\text {peak }}$ value shows a negative scale effect in a large range of joint sizes. Even so, positive scale effect or no scale effect may also be observed over a limited joint length range. There is a positive correlation between peak shear displacement and joint length, but a negative correlation between shear stiffness and joint length. These conclusions are applicable to both repeated and enlarged joints either under the CNL or CND condition.

Owing to shear dilatancy, there is little difference in the $\tau_{\text {peak }}$ between repeated and enlarged joints under the CNL condition, but an obvious difference under the CND condition. The shear dilatancy is completely restricted in this case. For the shear tests with low initial normal stress, the normal stress increment under the CND condition is 
much larger than that under the CNL condition. Consequently, the $\tau_{\text {peak }}$ under the CND condition is much higher than that under the CNL condition. However, when the normal stress is sufficiently high and shear dilatancy displacement is very small, the shear behavior of rock joints is consistent under CNL and CND conditions. In addition, compared to the $\tau_{\text {peak }}$ under CNL condition, the $\tau_{\text {peak }}$ increment under the CND condition is positively correlated with joint length for both repeated and enlarged joints, though the enlarged joints increase to greater extent than the repeated joints.

\section{Abbreviations}

CND: Constant normal displacement condition

CNL: Constant normal loading condition

CNS: Constant normal stiffness condition

JCS: Joint wall compressive strength ( $\mathrm{MPa})$

$\mathrm{JCS}_{0}$ : JCS value for the joint specimens in the laboratory (MPa)

$\mathrm{JCS}_{n}$ : JCS value for the large joints in situ (MPa)

JRC: Joint roughness coefficient (dimensionless)

$\mathrm{JRC}_{0}$ : JRC value for the joint specimens in the laboratory (dimensionless)

$\mathrm{JRC}_{n}$ : JRC value for the large joints in situ (dimensionless)

$L_{0}$ : Joint size in the laboratory (nominally $100 \mathrm{~mm}$ )

$L_{n}: \quad$ Joint size in situ

UCS: Uniaxial compressive strength ( $\mathrm{MPa})$

$\varphi_{\mathrm{b}}: \quad$ Basic friction angle $\left({ }^{\circ}\right)$

$\varphi_{\mathrm{r}}: \quad$ Residual friction angle $\left({ }^{\circ}\right)$

$\tau_{\text {peak }}$ : Peak shear strength of rock joints (MPa)

$\delta_{\text {peak }}$ : Peak shear displacement $(\mathrm{mm})$, the shear displacement when the $\tau_{\text {peak }}$ achieves

$d_{\text {peak }}$ : Peak dilatancy displacement $(\mathrm{mm})$, the dilatancy displacement when the $\tau_{\text {peak }}$ achieves

$\sigma_{n}: \quad$ Effective normal stress applied on a rock joint (MPa)

$k_{n}$ : Normal stiffness of the pressing plates during shear tests $(\mathrm{GPa} / \mathrm{m}$ or $\mathrm{MPa} / \mathrm{mm})$

$k_{s}$ : $\quad$ Shear stiffness of physical or numerical shear tests $(\mathrm{GPa} / \mathrm{m}$ or $\mathrm{MPa} / \mathrm{mm})$

$\omega: \quad$ The percentage of the normal stress increment under the CND condition

$K_{n}, K_{s}$ : Normal stiffness and shear stiffness of the particles in PFC2D

$\overline{K_{n}}$, Normal stiffness and shear stiffness of the parallel

$\overline{K_{s}}: \quad$ bond in PFC2D

$F_{n}, F_{s}$ : Normal contact force and shear contact force between two particles in PFC2D

$R_{\text {bond: }}$ Radius of the parallel bond in PFC2D.

\section{Data Availability}

The numerical simulation data used to support the findings of this study are available from the corresponding author upon request.

\section{Conflicts of Interest}

The authors declare no conflicts of interest.

\section{Acknowledgments}

This work was funded by the National Key Research and Development Program of China (Grant No. 2016YFC0801607), National Science Foundation of China (Grant Nos. 51525402, 51874069, 51904057, and 51761135102), Fundamental Research Funds for the Central Universities of China (Grant Nos. N170108028 and N180115009), and Postdoctoral Science Foundation of China (Grant No. 2018M641706). The financial support is gratefully acknowledged.

\section{References}

[1] S. Bandis, A. C. Lumsden, and N. R. Barton, "Experimental studies of scale effects on the shear behaviour of rock joints," International Journal of Rock Mechanics and Mining Sciences \& Geomechanics Abstracts, vol. 18, no. 1, pp. 1-21, 1981.

[2] N. Barton and S. Bandis, "Effects of block size on the shear behavior of jointed rock," in Proceedings of the 23rd US Symposium on Rock Mechanics (USRMS), American Rock Mechanics Association, pp. 739-760, Berkeley, CA, USA, August 1982.

[3] N. Barton and V. Choubey, "The shear strength of rock joints in theory and practice," Rock Mechanics Felsmechanik M canique des Roches, vol. 10, no. 1-2, pp. 1-54, 1977.

[4] N. Barton, "Review of a new shear-strength criterion for rock joints," Engineering Geology, vol. 7, no. 4, pp. 287-332, 1973.

[5] N. Barton and S. Bandis, "Review of predictive capabilities of JRC-JCS model in engineering practice," in Proceedings of the International Symposium on Rock Joints, pp. 603-610, Leon, Norway, June 1990.

[6] M. J. Azinfar, A. H. Ghazvinian, and H. R. Nejati, "Assessment of scale effect on $3 \mathrm{~d}$ roughness parameters of fracture surfaces," European Journal of Environmental and Civil Engineering, vol. 23, no. 1, pp. 1-28, 2016.

[7] M. Bahaaddini, P. C. Hagan, R. Mitra, and B. K. Hebblewhite, "Scale effect on the shear behavior of rock joints based on a numerical study," Engineering Geology, vol. 181, pp. 212-223, 2014.

[8] M. Castelli, F. Re, C. Scavia, and A. Zaninetti, "Experimental evaluation of scale effects on the mechanical behavior of rock joints," Rock Mechanics: A Challenge for Society, pp. 205-211, Taylor \& Francis, Abingdon, UK, 2001.

[9] N. Fardin, "Influence of structural non-stationarity of surface roughness on morphological characterization and mechanical deformation of rock joints," Rock Mechanics and Rock Engineering, vol. 41, no. 2, pp. 267-297, 2008.

[10] A. A. Giwelli, K. Sakaguchi, A. Gumati, and K. Matsuki, "Shear behaviour of fractured rock as a function of size and shear displacement," Geomechanics and Geoengineering, vol. 9, no. 4, pp. 253-264, 2014.

[11] D. Krsmanovic and M. Popovic, Large Scale Field Tests of the Shear Strength of Limestone. 1st ISRM Congress, Laboratorio Nacional de Engenharia Civil, Lisbon, Portugal, 1966.

[12] W. Leichnitz and O. Natau, "The influence of peak shear strength determination on the analytical rock slope stability," in Proceedings of the 4th International Congress on Rock Mechanics, pp. 335-341, Montreux, Switzerland, September 1979.

[13] J. Muralha and A. P. D. Cunha, "Analysis of scale effects in joint mechanical behavior," in Proceedings of the First 
International Workshop on Scale Effects in Rock Masses, pp. 191-200, Leon, Norway, 1990.

[14] A. P. D. Cunha, "Scale effects in the determination of mechanical properties of joints and rock masses," in Proceedings of the 7th ISRM Congress, pp. 311-318, Aachen, Germany, September 1991.

[15] H. R. Pratt, A. D. Black, and W. F. Brace, "Friction and deformation of jointed quartz diorite," in Proceedings of the Advances in Rock Mechanics: 3rd Congress of the International Society for Rock Mechanics, pp. 306-310, Denver, CO, USA, 1974.

[16] R. Yoshinaka, J. Yoshida, H. Arai, and S. Arisaka, "Scale effects on shear strength and deformability of rock joints," in Proceedings of the Second International Workshop on Scale Effects in Rock Masses, pp. 143-149, Lisbon, Portugal, 1993.

[17] R. Yoshinaka, J. Yoshida, T. Shimizu, and S. Arisaka, "Scale effect in shear strength and deformability of rock joints," in Proceedings of the 7th ISRM Congress, pp. 371-375, Aachen, Germany, September 1991.

[18] K. H. Kutter and F. Otto, "Influence of parallel and cross joints on shear behaviour of rock discontinuities," International Journal of Rock Mechanics and Mining Sciences \& Geomechanics Abstracts, vol. 28, no. 1, p. A7, 1991.

[19] M. J. A. L. Gomes, "Some new essential questions about scale effects on the mechanics of rock mass joints," in Proceedings of the 10th ISRM Congress: Technology Roadmap for Rock Mechanics, pp. 721-728, Sandton, South Africa, 2003.

[20] H. G. Locher and U. G. Rieder, "Shear tests on layered Jurassic limestone," in Proceedings of the 2nd Congress of International Society for Rock Mechanics, pp. 1-5, Belgrade, Serbia, 1970.

[21] G. P. Giani, A. M. Ferrero, G. Passarello, and L. Reinaudo, "Scale effect evaluation on natural discontinuity shear strength," Fractured and Jointed Rock Masses, pp. 447-452, A.A. Balkema, Brookfield, Lake Tahoe, CA, USA, 1992.

[22] S. R. Hencher, J. P. Toy, and A. C. Lumsden, "Scale dependent shear strength of rock joints," Second International Workshop on Scale Effects in Rock Masses, pp. 233-240, Taylor \& Francis, Lisbon, Portugal, 1993.

[23] F. Johansson, "Influence of scale and matedness on the peak shear strength of fresh, unweathered rock joints," International Journal of Rock Mechanics and Mining Sciences, vol. 82, no. 1, pp. 36-47, 2016.

[24] Y. Ohnishi and R. Yoshinaka, "Laboratory investigation of scale effect in mechanical behavior of rock joint," Fractured and Jointed Rock Masses, pp. 465-470, A.A. Balkema, Brookfield, Lake Tahoe, CA, USA, 1992.

[25] Y. Ohnishi, H. Herda, and R. Yoshinaka, "Shear strength scale effect and the geometry of single and repeated rock joints," in Proceedings of the Second International Workshop on Scale Effects in Rock Masses, pp. 167-173, Lisbon, Portugal, 1993.

[26] T.-S. Ueng, Y.-J. Jou, and I.-H. Peng, "Scale effect on shear strength of computer-aided manufactured joints," Journal of Geo Engineering, vol. 5, pp. 29-37, 2010.

[27] B. Indraratna, S. Thirukumaran, E. T. Brown, and S.-P. Zhu, "Modelling the shear behaviour of rock joints with asperity damage under constant normal stiffness," Rock Mechanics and Rock Engineering, vol. 48, no. 1, pp. 179-195, 2015.

[28] Y. Jiang, J. Xiao, Y. Tanabashi, and T. Mizokami, "Development of an automated servo-controlled direct shear apparatus applying a constant normal stiffness condition," International Journal of Rock Mechanics and Mining Sciences, vol. 41, no. 2, pp. 275-286, 2004.
[29] I. W. Johnston, T. S. K. Lam, and A. F. Williams, "Constant normal stiffness direct shear testing for socketed pile design in weak rock," Geotechnique, vol. 37, no. 1, pp. 83-89, 1987.

[30] R. Liu, S. Lou, X. Li et al., "Anisotropic surface roughness and shear behaviors of rough-walled plaster joints under constant normal load and constant normal stiffness conditions," Journal of Rock Mechanics and Geotechnical Engineering, vol. 12, no. 2, pp. 338-352, 2020.

[31] A. K. Shrivastava and K. S. Rao, "Shear behaviour of rock joints under CNL and CNS boundary conditions," Geotechnical and Geological Engineering, vol. 33, no. 5, pp. 1205-1220, 2015.

[32] Itasca Consulting Group, PFC2D (Particle Flow Code in 2 Dimensions) Version 3.1, Itasca Consulting Group, Minneapolis, MN, USA, 2004.

[33] N. Cho, C. D. Martin, and D. C. Sego, "A clumped particle model for rock," International Journal of Rock Mechanics and Mining Science, vol. 44, no. 7, pp. 997-1007, 2007.

[34] D. O. Potyondy and P. A. Cundall, "A bonded-particle model for rock," International Journal of Rock Mechanics and Mining Science, vol. 41, no. 8, pp. 1329-1364, 2004.

[35] M. Bahaaddini, G. Sharrock, and B. K. Hebblewhite, "Numerical direct shear tests to model the shear behaviour of rock joints," Computers and Geotechnics, vol. 51, pp. 101-115, 2013. 